\title{
Casos Tratados De Sífilis Congênita No Hospital Geral De Caxias Do Sul Entre 2010 E 2013
}

\author{
Filippini, F.B.; Krapf, M.O.; Carli, M.; Liz, F.M.; Zenil, A.P.D.; \\ Apresentador: Filippe Barcellos Filippini
}

\section{Resumo}

Introdução: Por ser uma doença completamente evitável mediante a detecção precoce em gestantes infectadas, a sífilis congênita (SC) é um importante marcador de saúde pública e de qualidade de assistência ao pré-natal. Contudo, observa-se um aumento progressivo da taxa de incidência de SC durante os últimos anos, chegando em 2011 a 3,3 casos/1.000 nascidos vivos. Abortamento espontâneo, nascimento pré-termo e óbito perinatal em até $40 \%$ dos casos, são os desfechos possíveis causados pelo Treponema pallidum. Os neonatos sobreviventes podem ficar assintomáticos em mais de 50\% dos casos, podendo tardiamente manifestar surdez, problemas visuais, retardo mental entre outras sequelas. Método: Foi realizado estudo retrospectivo nos neonatos em tratamento para sífilis congênita no Hospital Geral da Universidade de Caxias do Sul (HG-UCS) de 2010 até maio de 2013, com o objetivo de observar o número de neonatos com SC neste período e alertar sobre a necessidade do rastreamento precoce. Resultados: No período estudado, foram tratados 42 neonatos portadores de sífilis congênita conforme a definição proposta pelo Ministério da Saúde. A idade materna média foi de 26,4 anos (+/6,4 desvios padrão) e $50 \%$ das mães possuíam idade inferior a 25 anos. O nível de instrução materno era baixo em maior parte dos casos, sendo que $47,6 \%$ possuíam ensino fundamental incompleto ou eram analfabetas. Dentre os 42 casos, 7 foram em 2010, 8 em 2011, 13 em 2012 e 14 em 2013 (até o final do mês de maio). Conclusões: A Sífilis é uma doença sexualmente transmissível altamente disseminada no Brasil, estimando-se que 3,5\% das gestantes sejam portadoras. Os dados sobre SC mostram um padrão ascendente de tratamento predominante em mulheres jovens e de baixo nível de instrução. Esses resultados corroboram a necessidade de políticas de saúde e de educação das gestantes sobre a gravidade dessa patologia. Profissionais e estudantes da área da saúde devem ser alertados sobre a importância de um pré-natal adequado associado a realização de testes sorológicos como o Venereal Disease Research Laboratory (VDRL) no primeiro e terceiro trimestre além da testagem VDRL pré- parto. Isso consequentemente levaria ao diagnóstico e tratamento efetivo precoce, bem como a prevenção de possíveis sequelas irreversíveis.

\section{Referência:}

Filippini, F.B.; Krapf, M.O.; Carli, M.; Liz, F.M.; Zenil, A.P.D.;. Casos Tratados De Sífilis Congênita No Hospital Geral De Caxias Do Sul Entre 2010 E 2013. In: II Congresso Brasileiro de Medicina Hospitalar - II CBMH [= Blucher Medical Proceedings, vol.1, num.5] São Paulo: Editora Blucher, 2014. p.26

DOI 10.5151/medpro-II-cbmh-018 